SREĆKO MIHAILOVIĆ, viši naučni saradnik

Institut za društvene nauke

Beograd, Kraljice Natalije 45

UDK 316.644:329(497.11)"1990/2011"

\title{
KAKO GRAĐANI SRBIJE VIDE DEMOKRATSKU STRANKU U POSLEDNJOJ DECENIJI 20. VEKA I PRVOJ DECENIJI 21. VEKA
}

\begin{abstract}
APSTRAKT: Članak razmatra ideološki profil, karakter i imidž Demokratske stranke, na bazi izvršene ankete. Istaživanje daje određenje stranke u ideloškom kontekstu, poziciju njenih pristalica i očekivanja. Takođe se uočava da je levodesno opredeljenje zasnovano na površnim, nejasnim i neodređenim impresijama, koje su stalnog karaktera. Autor zaključuje da Demokratskoj stranci treba još mnogo toga da bi je javnost percipirala kao stranku levice, kao i da su pristalice te stranke u gotovo svim posmatranim godinama imale pozitivniji odnos prema ,drugima“ od pristalica ostalih stranaka prema njima.
\end{abstract}

Kjlučne reči: Srbija, građani, Demokratska stranka, ideologija, imidž

Srbija se već dva veka susreće sa kobnim pitanjem - pitanjem državnih okvira, državnih granica; Srbija dva veka stvara državu i vodi bezbrojne ratove. Nacionalizam idu uz to, a kada je tako onda je sve ostalo, $i$ sam život, u senci te crne rupe koja guta energiju i pamet elite i naroda. Zaostajanje u privrednom razvoju / nizak životni standard i deficit demokratije - upravo se objašnjavaju „zauzetošću“ državnim granicama. Drugi narodi, i elite drugih naroda, stremili su ka boljem životu, ka demokratiji, a naša elita i naš narod - ka većem državnom prostoru! ${ }^{1}$ Ako ovome dodamo i niske kapacitete domaće elite, onda mnoge stvari mogu da nam budu znatno jasnije. Na to stanje elite je davno upozorio Milan Grol kada je podsetio da su još pre Prvog rata u Kragujevačkom okrugu, jedan za drugim, poslanički kandidati bili Stojan Novaković, Jaša Prodanović i Jovan Skerlić. Kada se ove veličine uporede sa kasnijim kandidatima vidi se sva „tragedija našeg javnog života“! Mogli bismo danas da dodamo da kada se pomenuti kandidati uporede sa današnjim, bilo gde, poslaničkim kandidatima, da se vidi sva komedija od našeg javnog života!

${ }^{1} \mathrm{U}$ vremenima kada pitanje državnog okvira nije bilo hegemonijsko pitanje (doba vladavine Komunističke partije), imali smo suspenziju političke demokratije (uz izvesno povećavanje socijalne demokratije) i stalno poboljšanje života (bez obzira na čijim parama se to zasnivalo). 
O karakteru jedne političke stranke može da se sudi na osnovu različitih kriterijuma. Prevlađuje sud na osnovu praktične politike date stranke i na osnovu njenog programa. $^{2}$ Autor i jednog i drugog kriterijuma je stranačko vođstvo. Naravno, nije dovoljno znati na osnovu čega se sudi već je nekada mnogo važnije znati ko sudi i sa kakvim namerama. Za namere se mora pitati čak i kada sude ljudi od nauke, a kamoli kada su u ulozi „sudije“ ljudi iz medija ili politički protivnici date stranke ili razni ,spin-doktori“.

Danas se najčešće sudi na osnovu ponašanja stranačkog rukovodstva, a još češće na osnovu izjava tog rukovodstva. Postoji težnja da se sudi na osnovu učinjenog, a ne na osnovu zapisane namere o činjenju; dakle na osnovu konkretne stranačke politike, a ne na osnovu programa date stranke. U praksi, međutim, prevladava „,novinarska logika“. Mediji praktikuju da javnosti prikažu određenu stranku na osnovu identiteta stranke koji objavljuje njeno rukovodstvo. Time se javnost inficira nekritičkim predstavama stranačkog rukovodstva o samom sebi (govori, izjave, saopštenja, intervjui). Nebitno je, pri tom, da li je reč o samozavaravanju ili varanju sa određenom namerom. U krajnjoj liniji nebitno je da li se o jednoj stranci sudi na osnovu njene samopredstave (koja je uvek izraz željenog identiteta) ili na osnovu mišljenja njenih političkih protivnika (takođe izraz po-

${ }^{2} \mathrm{U}$ strogom istraživanju, banalno je i pokušavati sa stranačkim programom kao indikatorom identiteta, politička praksa je ovde vrhovni sudija. Banalno je ovde pozivati se na Lenjina i na Bernštajna. Treba se pozivati na starije istraživače, one s početka 20. veka, iz zlatnog doba proučavanja stranaka, kada su tek pojedinci nazirali ono što će potom biti najčešća stranačka praksa. To je doba kada se zaključivalo na osnovu „najrazvijenijih slučajeva“, američkih partija ili slučaja nemačke socijaldemokratske partije. Tako je Maks Veber napisao u Privredi i društvu da je cilj partija „samo da putem izbora dovedu svoga vođu na rukovodeći položaj, da bi on zatim poveravao državne službe svojim pristalicama: činovničkom i propagandnom aparatu partije“ (1976: 436). Slično je mislio i Slobodan Jovanović kada je napisao da se aktivnost stranke svodi na nastojanje da se pošto-poto dođe na vlast a onda da se na njoj što duže zadrži, a sve to i po cenu gubitka političke doslednosti i identiteta. Entoni Dauns je pedesetih godina 20. veka tvrdio da partije formulišu politiku da bi dobile izbore, a ne osvajaju vlast da bi formulisale politiku! - Program partije manje ili više ostaje u njenoj identitetskoj funkciji. Političke stranke se gotovo nikad ne odriču programa u celini, one ga „dopunjavaju“, ,popravljaju“, ,,aktuelizuju“. On, dakle, ostaje na pijedestalu ključnog elementa u prepoznavanju stranke kao takve. Može se govoriti o najmanje šest funkcija partijskih programa: 1) funkcija stranačkog identiteta, 2) funkcija okvira i orijentira za utvrđivanje i vođenje stranačke politike, 3) funkcija kontrolnog kriterijuma za ocenu politike koju stranka vodi, 4) program stranke u funkciji imidža stranke, 5) program stranke u funkciji identifikacije sa strankom, i 6) program stranke u funkciji individualne orijentacije. (Mihailović, Srećko. 2005. „Mesto stranačkih programa u identifikaciji građana sa političkim strankama“, u: Mihailović, Srećko (ur.). Programski identiteti socijaldemokratskih stranaka. Beograd: Socijaldemokratski klub i Friedrich Ebert Stiftung, 29-30). - Uostalom, treba pogledati obrazloženja za izdvajanje od stranke-matice koja su navodili stranački prvaci koji su se „otcepili“ od Demokratske stranke: Nikola Milošević, 1990 Srpska liberalna stranka; Vojislav Koštunica, 1992 - Demokratska stranka Srbije; Vladan Batić prvo u DSS, a onda 1997 - Demohrišćanska stranka Srbije; Dragoljub Mićunović, 1996 - Demokratski centar; Slobodan Vuksanović, 2001 - Narodna demokratska stranka Srbije; Čedomir Jovanović, 2005 - Liberalno-demokratska partija. 
željnog identiteta date stranke ili onog koji je protivniku koristan u političkoj borbi) ili na osnovu mišljenja kreatora javnog mnjenja (a ono je na klackalici između potreba da se javnost informiše o nečemu i potrebe da se ubedi u nešto; bilo koji motiv da je u pitanju, mediji se rukovode logikom profita) - valenca i jednog i drugog i trećeg suda, gotovo je ista!

U svakom slučaju izvor predstave o karakteru date stranke, stvaran ili spinovan, jeste rukovodstvo stranke, direktno (razni oblici samopredstavljanja, politika stranke) ili indirektno (program). Ono što se retko radi jeste procenjivanje karaktera jedne političke stranke na osnovu mišljenja, stavova i vrednosnih opredeljenja njenih sledbenika. Dakle, stranačko rukovodstvo, stranački prvaci, a ne sledbenici stranke (članovi, glasači, simpatizeri). Takva evaluacija resursa za zaključivanje o karakteru stranke ima valjanih argumenata i nije stvar u njenom poricanju već u tome što je ona nedovoljna, pre svega jer je nepotpuna, pa utoliko i netačna.

Redukcija resursa evaluacije stranačkog karaktera na (aktuelno) stranačko rukovodstvo (program stranke, politika stranke, samopredstave stranačkih prvaka o svojoj stranci), zasnovana je na manjkavom pravilu po kojem smo mi onakvi kakvi sami sebe vidimo, a ne, na primer, da smo mi onakvi kakvim nas drugi vide! Očito, ovom redukcijom zanemaruju se interni činioci karaktera jedne stranke, kao što su sledbenici stranke i stranačka istorija i tradicija, ukupni kapaciteti stranke za političko delanje, objektivna dostupnost stranačkih ciljeva i drugi. Zanemaruju se i eksterni činioci karaktera stranke, to jest u kojoj konstelaciji društvenih odnosa deluje data stranka, kako stranku vide javnost i stručna javnost, a naročito kako je vide drugi akteri u podsistemu politike (pre svega, konkurenti za isto dobro u politici).

Obrazloženja redukcije retko su jedinstvena, mnogo češće su pojedinačna. Tako se, na primer, isključenje sledbenika stranke kao resursa za evaluaciju karaktera stranke obrazlaže jednosmerno shvaćenim uticajem stranačkog rukovodstva na stranačke sledbenike. Time se zanemaruje uticaj stranačkih sledbenika na stranačko rukovodstvo i previđa vremensko zaostajanje u prihvatanju nove stranačke politike (posebno kada su u pitanju zaokreti u toj politici) od strane sledbenika, kao i gubitak (i eventualni dobitak) članova zbog nove politike, odnosno zaokreta u politici.

U krajnjem, iza minimiziranja, pa i zanemarivanja sledbenika stranke kao resursa relevantnih podataka o samoj stranci, stoji za mnoge političke stranke tipično instrumentalno shvatanje uloge sledbenika (a potom i birača i građana uopšte) i odbacivanje mogućnosti da oni utiču na bilo šta u stranci. A kad god se ova činjenica pomene, kako to već ide uz naš epski karakter, sledi podsećanje na Njegoša i Gorski vijenac: ,...e je raja ka ostala marva“ (...) „pučina je stoka jedna grdna...". Kao da su naši današnji stranački prvaci sledbenici Selim-vezira koji je svojedobno Crnogorce učio pomenutim „istinama“. I u Demokratskoj stranci je zaboravljano i zaboravlja se opredeljenje koje je njen lider Zoran Đinđić izgovorio na sednici Glavnog odbora stranke 10. februara 2002: „Ako želimo da bude- 
mo jedna moderna, dinamična i politička organizacija, taj dinamizam i ta energija dolazi od članstva, ne od funkcionera. Funkcioneri su poglavice. Poglavice bez Indijanaca nisu pleme, nego muzej voštanih figura. Članstvo je suština vitalnosti jedne organizacije.“ (Istorija Demokratske stranke 1989-2009. Dokumenti, 230).

\section{Ideologija stranke i ideologija pristalica}

Političke stranke s jedne strane izražavaju određenu smesu (koaliciju) interesa, potreba i vrednosti koje postoje u socijalnoj strukturi datog društva, s druge strane one povratno utiču i preoblikuju izvornu smesu interesa, potreba i vrednosti (Feedback). U krajnjem, stranke se bave nastojanjem da oblikuju, prošire i da prodube ideološku / političku interpretaciju određenih (grupnih) potreba interesa, vrednosti i dr. Interpretativna šema izvorne smese interesa, potreba i vrednosti, u okviru našeg koncepta, biće shvaćena (definisana) kao ideologija pristalica. Na drugoj strani, interpretativna šema interesa, potreba i vrednosti kojom se rukovodi partijsko vođstvo u svojoj politici i koju nameće svojim pristalicama kao stranačku politiku, biće definisana kao ideologija stranke. Ove dve ideologije su u većoj ili manjoj meri podudarne i stranka uvek, po pravilu, nastoji da iskaže istovetnost, bez obzira na stvarne razlike. U vreme predizborne kampanje stranka teži da razliku između ovih dveju ideologija svede na minimum, kako bi pokazala da se upravo ona i jedino ona dosledno bavi ostvarivanjem interesa, potreba i vrednosti svojih pristalica, ali i „mnogih drugih građana koji nam pripada$j u$ a da to i ne znaju“.

Prva ideologija je relativno stabilna, dok je druga fleksibilna. U ideologiju pristalica je ugrađeno nastojanje da stranka vodi politiku doslednu njihovoj ideologiji. U ideologiju stranke je pak ugrađeno nastojanje da se (u borbi za izborni uspeh, tj. vlast) širi krug pristalica i po cenu promene ideologije kako bi ona odgovarala i novim pristalicama. Ovakav trend doveden do svog zenita daje tako poopštenu ideologiju koja ima pretenziju da odgovora svim „pojedinačnim“ ideologijama, odnosno nijednoj posebno (Catch-all party).

Razlikovanje ideologije pristalica i ideologije stranaka važno je $u$ još jednom domenu, u komparaciji modernih zapadnoevropskih stranaka i stranaka u postkomunističkim zemljama - zemljama u tranziciji ili zemljama tek izašlim iz najžešće faze tranzicije. Iako je, verovatno, prilično tačna teza da stranke u postkomunističkim zemljama moraju proći sve faze razvoja modernih zapadnih stranaka, ipak stvari izgledaju nešto drukčije ukoliko konsekventno i diferencirano pratimo razvoj ideologije stranaka i ideologije građana (tj. stranačkih pristalica i potencijalnih stranačkih pristalica). Klaus fon Bem u analizi zapadnih iskustava govori o deideologizaciji stranaka i programskom približavanju političkih strana$\mathrm{ka}$ - on inače ideologizovanost vezuje za period ranih masovnih stranaka. Shodno tome on smatra da je već sredinom 20. veka opala propagandna snaga ideologije. Ali, teza o „kraju ideologije“ brzo se pokazala pojednostavljenom. „Tek što je postavljena nastao je novi val reideologizacije u strankama zapadne demokra- 
cije“ (2002: 171). Pri tome nije bila reč o deideologizaciji, već su ideologije postale kompetitivnije i delatno relevantnije. No, autor ipak zaključuje da u eri modernih profesionalnih stranaka (period od 80-ih godina prošlog veka) ideologija nema šta da traži. Iako Bem deideologizaciju prvenstveno vezuje za birački nivo (od stranke nekontrolisan nivo), a ne za stranački, argumentacija koju navodi vezana je gotovo isključivo za stranke. No, ukupno uzev, ukoliko pod ideologijom ne podrazumevamo samo viziju već i određene vrednosne strukture, ukoliko dosledno i argumentovano istražujemo ideologije stranačkih pristalica (aktuelnih i potencijalnih) i ako ispitujemo ideologiju stranaka na osnovu političkog ponašanja stranke, a ne samo na osnovu programa i programskih izjava - onda teško da može da se govori o „kraju ideologije“ ne samo u postkomunističkim zemljama već i u zapadnoevropskim. Uostalom, u najvećem broju slučajeva iza rasprava o „kraju ideologije“ i / ili deideologizaciji političkih stranaka stoje terminološki nesporazumi! Na kraju, danas najpoznatiji istraživač vrednosti R. Inglehart u svojim studijama svetskih vrednosti ističe sve centralnije mesto vrednosti u sferi politike, pa time i političkih stranaka (o tome videti Pantić, 2003).

\section{Kakve su u ideološkom smislu pristalice DS a kakva je Demokratska stranka}

Postoje barem tri razloga za ispitivanje mišljenja, stavova i vrednosnog (i / ili ideološkog) profila stranačkih pristalica pri utvrđivanju karaktera određene stranke: (1) ako je i jednim pa i manjim delom, politička stranka onakva kakvi su njeni sledbenici, onda ima smisla ispitivanje sledbenika stranke da bi se saznalo kakva je sama stranka; (2) ako je ideal da politika moderne demokratske stranke bude zasnovana na sintezi programske orijentacije, opredeljenja građanstva, opredeljenja pristalica, kapaciteta date stranke i sagledavanja realnih mogućnosti (sprovodljivost određene politike), onda ima smisla baviti se političkim i vrednosnim orijentacijama sledbenika date stranke; (3) ako barem u jednom trenutku, ma koliko taj trenutak bio kratak, stranačko vođstvo vodi računa i oslanja se na sledbenike, a to se dešava u vreme izborne kampanje i samih izbora, onda ima smisla da se ideološko-politički karakter sledbenika prihvati kao kriterijum pri određivanju karaktera određene stranke.

Praktično-politički gledano, demokrate su se u svom životu dugom dve decenije kretale od stranke centra prvo malo udesno, pa nazad u centar i na kraju malo ulevo. To se, međutim, ne vidi uvek u programskim izjavama i u programu stranke. Dragoljub Mićunović na osnivačkoj skupštini stranke (3. februra 1990) govori o „novoj stranci“, ali i o „stranci kontinuiteta“ sa starom Demokratskom strankom; u Pismu o namerama (3. februar 1990) stranka se samodefiniše programskim ciljevima; u Izbornom programu iz 1992. stranka vidi sebe kao „modernu partiju građanskog centra“; u 2001. godini nalazimo i razvijanje određenja DS kao stranke centra, ali i napuštanje ideološkog pozicioniranja stranke (Program iz oktobra 2001); u poslednjim Đinđićevim istupima vidimo zaokret ka so- 
cijaldemokratiji; socijaldemokratski profil se definitivno inauguriše u drugoj polovini ove decenije (videti, na primer, Izborni program iz 2007). Godine 2002, programski trendovi su imali odraz i u odnosu prema Socijalističkoj internacionali (SI). Demokratska stranka je donela odluka da podnese kandidaturu za članstvo u SI, a 2003. dobila je u njoj status posmatrača. Etički komitet Socijalističke internacionale doneo je 2005. godine odluku da Demokratska stranka postane punopravna članica SI, a 2008. na kongresu u Atini to je i formalno potvrđeno. Time je okončan put Demokratske stranke ka punopravnom članstvu u ovoj svetskoj organizaciji radničkih, socijalističkih i socijaldemokratskih partija građanske levice. ${ }^{3}$

$\mathrm{Na}$ desetogodišnjicu 5. oktobra, predsednik Demokratske stranke Boris Tadić najavio je pomeranje političkog težišta DS ulevo, prema snažnijem učešću u socijalnom dijalogu i (,organskom“) oslanjanju na sindikate. ${ }^{4}$ Bio je to nešto jači potez na putu koji je (stidljivo) naglašavan još od početka ove decenije - putu koji vodi ka socijaldemokratskom konceptu stranke.

A šta je sa pristalicama Demokratske stranke? Gde su oni bili pre neku godinu, a gde su danas? Pogotovo u donekle šizofrenom okruženju u kojem je Srbija (i praktična politika stranke koju slede) bila na desnom putu, dok je programski i ideološki stranka koju slede išla levim putem! Kakvi su, dakle, sledbenici / simpatizeri Demokratske stranke? Posmatranje ograničavamo na poslednju deceniju 20. veka i na prvu deceniju 21. veka (na trajanje druge Demokratske stranke, koje je gotovo izjednačeno sa vremenom trajanja prve Demokratske stranke). Nastojaćemo, u meri u kojoj to podaci omogućavaju, da ostvarimo uvid u stanje

${ }^{3} \mathrm{O}$ ideološkim manevrima DS videti i sledeće ocene. „U proteklom periodu od petnaest godina, egzemplarno je pozicioniranje Demokratske stranke. Potekla iz, uslovno rečeno, „desnog“ - liberalno-demokratskog polja ova će partija ispoljiti veliku dozu realpolitičke pragmatičnosti u evoluciji svoje ideološke matrice. (...) Demokratska stranka (je) jedinstven primer među relevantnim partijama u Srbiji, koja će se usuditi da pravi česte manevre na ideološkom kontinuumu levodesnog pola partijskog sistema Srbije. (...) U programu iz 1995, godine DS se deklarisala kao stranka socijalne odgovornosti i solidarnosti usprotivivši se veličanju tržišta kao recepta za sve bolesti. Rečeno je da se DS ne zalaže za „surovi, laissez-faire kapitalizam XIX veka“, već za savremeno liberalno društvo zapadnoevropskog tipa u kome se država brine o svojim građanima (...). U ranijim programima DS je zagovarala socijaldemokratski model socijalne politike, deklarišući potrebu insistiranja na redistribuciji prilika, odnosno, jednakosti šansi. Međutim, po osvajanju vlasti, u novom programu iz 2001. DS će napustiti i ideološke pozicije centra i ekspertski koncept svog prethodnog programa iz 1995. Distributivna formula u najnovijem programu DS je sasvim kratka i glasi: „Srbija socijalne solidarnosti“. DS smatra da je zarad potpunije sreće društva, pa time i pojedinaca, neophodno stalno voditi računa o uspostavljanju jednakih šansi za sve. Obrazloženo je da se nikome ne garantuje uspeh, ali da svako mora dobiti svoju šansu da ga postigne. Oni koji tu šansu ne iskoriste, zbog subjektivnih ili objektivnih razloga, zaslužuju određen stepen solidarnosti - od toga da im se omogući minimum socijalne zaštite, pa do toga da im se pruži nova šansa." (Vukomanović, 2007: 93, 96, 97)

${ }^{4}$ Ovde treba podsetiti na Načela zajedničkog delovanja Demokratske stranke i UGS Nezavisnost koja su 13. jula 2004. potpisali Branislav Čanak i Boris Tadić, a od kojih u praksi nije bilo ništa. Možda je i to jedan od razloga zašto su sindikalni prvaci hladno reagovali na najnoviju „ponudu“ Demokratske stranke. 
svesti sledbenika Demokratske stranke, idealno bi bilo u pet vremenskih isečaka: 1990, sredina devedesetih, 2000, sredina prve decenije novog veka i 2010. godine, a faktički ćemo se koncentrisati na nalaze jednog istraživanja iz sredine ove decenije.

\section{Demokratska stranka između centra i levice}

Demokratska stranka je stranka dugog trajanja. Demokrati i radikali imaju najdužu istoriju - polovinu od jednog veka srpskog višepartizma. Ona je, zajedno sa radikalima, obeležila partijski život Srbije i Jugoslavije između dva svetska rata, isto kao što je sa ovim radikalima (koji teško mogu baštiniti kontinuitet sa Pašićevim radikalima), obeležila partijski život Srbije u poslednjoj deceniji.

U svojoj poluvekovnoj istoriji Demokratska stranka je više bila stranka centra nego stranka levice ili levog centra; pre bi se moglo reći da je bila stranka centra koja je povremeno težila levo, ali i da je više sarađivala sa strankama levice nego sa strankama desnice (ne uzimajući samo ovaj drugi život i saradnju sa SPS, već i period između dva rata i saradnju sa socijaldemokratama).

U ovom kontekstu, prvenstveno nas interesuje kako pristalice Demokratske stranke vide njen i svoj položaj u ideološko-političkom levo-desno (LD) prostoru. No, prethodno je pitanje: Da li građani Srbije uopšte i znaju šta je u politici „levo“" a šta „desno“? U odgovoru na ovo pitanje pozivam se na rezultate svog istraživanja iz 2006. godine. U tom istraživanju tražili smo, putem ličnog razgovora, od 2.081 punoletnog građanina Srbije ${ }^{5}$ da kažu gde sebe vide na skali koja ima 10 podeljaka - na levoj strani pet i na desnoj pet, sa nulom u sredini i napomenom da petica na levoj strani označava krajnju levicu, da nula označava centar, a petica na desnoj strani označava krajnju desnicu. Pitanje je formulisano na sledeći način: „Kada se govori o politici često se upotrebljavaju izrazi „levo“ i „desno“. Pogledajte ovu skalu pa mi kažite gde Vi vidite sebe?“" Pri tom je ispitaniku bila predočena pomenuta skala. (Ispitanici su mogli da odgovore sa „Ne znam“, ili da kažu da ne prihvataju takvu podelu ili da je sve tako zbrkano u politici da se oni tu ne snalaze. Mi smo sve ovakve odgovore svrstali u kategoriju ,Ne zna“.)

Ukupno je odgovore dalo $70 \%$ ispitanika, dok je 30\% nije odgovorilo na ovo pitanje. ${ }^{6}$ Među tom nepunom trećinom od onih sa odgovorom „Ne znam“ da-

${ }^{5}$ Istraživanje je za potrebe Istraživačko-izdavačkog centra Demokratske stranke realizovano od 12. do 18. oktobra 2006. na kvotnom uzorku od 2.081 punoletnog građanina Srbije. Podaci su prikupljeni putem ličnog intervjua (face to face). Upitnik je sadržao 121 pitanje, a intervjue su obavili terenski saradnici Udruženja za unapređenje empirijskih istraživanja. Rukovodilac istraživanja bio je Srećko Mihailović, sociolog.

${ }^{6}$ Poređenje sa evropskim zemljama ne daje jednoznačne nalaze. Najbolji rezultati u Srbiji $(1990,2001$ i 2006) jesu u ravni nalaza iz evropskih zemalja iz 1970-ih godina. Sameravanje rezultata iz Srbije sa rezultatima za postkomunističke zemlje iz 1990-91. godine pokazuje da je Srbija 
leko najviše je onih koji su upravo tako i rekli, a manji broj je odgovorio kako ne mogu da se u ovome snađu, da ih politike ne interesuje, da smatraju da je ovakvo merenje neprimereno našim uslovima itd.

U osnovnim kategorijama zanimanja, postotak onih koji ,,ne znaju“ da se snađu u ideološkom levo-desno prostoru kreće se između jedne i dve petine. Najmanje je onih koji „ne znaju“ među stručnjacima (21\%), a potom među službenicima (23\%). U sredini su punoletni učenici i studenti i tehničari (po 26\%), kao i KV i VKV radnici (28\%). Najčešće „ne znaju“ poljoprivrednici (36\%) i domaćice (44\%). Ovoj kategorizaciji zanimanja ispitanika možemo dodati i tri grupe iz klasifikacije radnog statusa: male privatnike sa $19 \%$ onih koji „ne znaju“, nezaposlene sa $31 \%$ onih koji „ne znaju“ i penzionere sa $36 \%$ onih koji „,ne znaju“. I ovde je došla do izražaja uobičajena distribucija odgovora, veoma slična onim koji se dobijaju kad god se ispituje poznavanje politike ili obaveštenost o raznim političkim pitanjima. Čak se može reći da se slične distribucije dobijaju u ispitivanjima političkog aktiviteta ili socijalne participacije. Po svemu sudeći, podela na ove društvene grupe izražava dublje socioklasne podele koje su u uskoj vezi sa raznim oblicima političke participacije, pa i sa ovom o kojoj je ovde reč.

Već je iz datih podataka vidljiva povezanost obrazovnog nivoa sa snalaženjem u političkom prostoru. Među onima bez škole i sa nezavršenom ili završenom osnovnom školom ima $41 \%$ onih koji „ne znaju“, među onima sa „radničkim školama“ $-25 \%$, sa srednjim (četvorogodišnjim) školama $-27 \%$, dok među onima sa višom školom ili fakultetom svaki peti $(21 \%)$,ne zna“.

Navedeni podaci ukazuju na to da je „nesnalaženje“ u ideološkom LD prostoru povezano sa statusom građana. To potvrđuju i podaci o prosečnim mesečnim primanjima po članu porodice. Prosek onih koji se „snalaze“, koji „znaju“ je 156, a onih koji „,ne znaju“ 136 eura ( 1 euro $=80$ dinara). Isti je smer i povezivanja osećaja gubitništva i dobitništva. Svaki treći $(36 \%)$ među onima koji se oseća kao „gubitnik“ kaže da „ne zna“, dok je manje takvih među „dobitnicima“ - svaki peti (21\%). I na kraju potvrdu nalazimo i u odgovorima na pitanje „Kako živite vi i vaša porodica?“. Među onima koji su izjavili da „dobro žive“ ima 19\% onih koji ne znaju da se snađu u ideološkom LD prostoru, a među onima koji kažu da žive „nepodnošljivo“ $-39 \%$.

Stariji ispitanici se nešto lošije snalaze u ideološkim podelama. Dok oni koji umeju da se „samosvrstaju“ u ideološkom LD prostoru u proseku imaju 44 godine, dotle oni koji se „ne snalaze“ imaju u proseku 46 godina. U stvari, sličan je stepen ,nepoznavanja“ u svim starosnim grupama (od 26 do 29\%), osim onih koji imaju 60 i više godina među kojima je 37\% onih koji „ne znaju“.

Kao svojevrstan zaključak, možda izgleda nalaz o povezanosti zadovoljstva životom i samoidentifikacije na ideološkoj skali levo-desno. Među onima

gotovo na samom vrhu. Činjenica je, međutim, da su nalazi u Srbiji izuzetno nestabilni i da su varijacije ogromne. 
koji su veoma nezadovoljni svojim životom ima $44 \%$ onih koji se ne snalaze na pomenutoj skali, a među onima koji su veoma zadovoljni - 14\%.

Kulturne navike (indicirane pomoću pet pokazatelja - gledanje TV, čitanje novina, kupovina knjiga, odlazak u pozorište, korišćenje interneta) takođe su značajno povezane sa mogućnošću ideološke samoidentifikacije. Među građanima koji imaju veoma razvijene kulturne navike nalazimo $15 \%$ onih koji ne mogu da se orijentišu u ideološkom LD prostoru, a među onima koji nemaju kulturne navike $-56 \%$ ili gotovo četiri puta više.

Sposobnost samoprepoznavanja u ideološko-političkom prostoru, preko levo-desne podele, povezana je prvenstveno sa političkim i socijalnim aktivitetom i sa socijalnim statusom pojedinca. Izneti zaključak upućuje i na povezanost poznavanja ideološko-političke LD podele sa partijskom identifikacijom, odnosno sa izbornom orijentacijom ispitanika. Najveći broj onih koji „ne znaju“ nalazimo među onima koji najavljuju izbornu apstinenciju - tu čak svaki drugi „ne zna“, među onima koji su neodlučni i još ne znaju da li će izaći na izbore - svaki treći, među onima koji neće da kažu za koga će glasati - 28\%, a među izborno orijentisanim participantima - 17\% (odnosno $14-21 \%$ među izbornim pristalicama četiri relevantne partije). Među ispitanicima koji nemaju sebi blisku političku stranku, $41 \%$ je onih koji ne znaju da se svrstaju u levo-desni kontinuum. Iz levodesnih podela sami sebe isključuje $22 \%$ pristalica SPS, $18 \%$ - DSS, $15 \%$ - SRS i $13 \%$ pristalica Demokratske stranke. U istraživanju iz 2010. godine iz levo-desnog samoprepoznavanja sebe isključuje $32 \%$ pristalica DS (kod naprednjaka $36 \%$, a na opštem nivou čak 54\%).

Tabela 1 - ,,Snalaženje“ na levo-desnoj ideološkoj skali (u \%)

\begin{tabular}{|l|r|r|r|r|}
\hline $\begin{array}{l}\text { Godina } \\
\text { istraživanja }\end{array}$ & $\begin{array}{l}\text { Orijentiše se } \\
\text { na LD skali }\end{array}$ & $\begin{array}{l}\text { Nije u stanju } \\
\text { da se orijentiše }\end{array}$ & $\begin{array}{l}\text { Ukupno } \\
\text { ispitanika }\end{array}$ & $\begin{array}{l}\text { Istraživačka } \\
\text { agencija }\end{array}$ \\
\hline 2002, maj & 43 & 57 & 100 & CPA \\
\hline 2002, novembar & 52 & 48 & 100 & CESID \\
\hline 2004, februar & 55 & 45 & 100 & FOSDI \\
\hline 2004, maj & 54 & 46 & 100 & CESID \\
\hline 2005, novembar & 47 & 53 & 100 & CESID \\
\hline 2006, oktobar & 70 & 30 & 100 & IIC DS \\
\hline 2010, septembar & 46 & 54 & 100 & CESID \\
\hline
\end{tabular}

Prilično nedoumica donosi uvid u nalaze istraživanja javnog mnjenja u poslednjih nekoliko godina, a koja sadrže nalaze o proporciji onih koji se „snalaze“ na levo-desnoj ideološkoj skali (tabela 1). Ti nalazi govore o relativno ujednačenim nalazima 2002-2005. godine kada se proporcija onih koje se samopozicioniraju kreće $43-55 \%$ i ,iskakanju“ nalaza iz 2006. godine kada utvrđujemo da se $70 \%$ ispitanika pronalazi na levo-desnom kontinuumu, da bi 2010. godine ponovo imali pad na ranije stanje. Osim eventualnih razlika u uzorcima, jedina značajnija razlika je u tome što smo u istraživanju iz 2006. godine koristili ,grafičku 
karticu“, to jest nacrtanu kontinuelnu skalu sa 11 tačaka koje su označavale različite pozicije u levo-desnom kontinuumu i što je tu „sliku“ ispitanik imao u rukama, odnosno ispred sebe. Što se tiče političke prakse u Srbiji, sa stanovišta eventualnih razlika u toku tih godinu dana ne može se reći da je bilo bitnih promena koje su mogle da uslove povećanje ,ideološkog samorazumevanja“, osim što je Demokratska stranka nešto više naglašavala svoju socijaldemokratsku orijentaciju, poziciju „levo od centra“ i ređe „levog centra“, kao i članstvo u Socijalističkoj internacionali. Stoga iznosim nekoliko mogućih objašnjenja činilaca vezanih za proporciju „samorazumevajućih“ u odnosu na one koji to nisu.

(1) Potreba za ideološkom orijentacijom. Da li je ljudima potrebna levodesna dihotomija ili imaju nešto što je jednostavnije i dovoljno orijentišuće, ili im nije potreban nikakav orijentir u ravni politike jer se nalaze izvan njega? Zašto bi, na primer, građani SAD ili Velike Britanije osećali potrebu za levo-desnim samosvrstavanjem kada imaju dihotomne partijske sisteme? Ovome se kao argument može dodati i to da u Americi levo-desna šema i nije popularna. Na individualnom planu, ova šema je nebitna za one koji nisu dospeli do politike (za one koji žive u predpolitičkom dobu), za one koji su izašli iz politike (depolitizovani), ali i za one građane koji imaju ekstremno pragmatičan odnos prema politici (ekstremni utiltarizam ne trpi nikakva druga merila prema bilo čemu; utilitaristi nemaju potrebe za bilo kakvom ideologijom; korist je njihova jedina i isključiva ideologija - do ut des!).

(2) Intenzitet ideološke polarizacije. Ideološka levo-desna orijentacija je nebitna ili je manje važna u zemljama u kojima dominiraju druge polarizacije. U ovom kontekstu se može razumeti niska korelacija levo-desnog ideološkog samosvrstavanja i izborne orijentacije u slučaju Severne Irske. ${ }^{7}$ Relativno nisko snalaženje na levo-desnoj ideološkoj skali u slučaju građana Srbije takođe se može objasniti intenzitetom drugih socijalnih, političkih i vrednosnih raskola. Ako, na primer, u političkom životu dominira podela na „patriote“ i ,izdajnike“, na „Evropljane“ i „Antievropljane“, ne može se očekivati da će doći do punog izražaja levo-desna polarizacija!

(3) Kapaciteti orijentacije. Ukoliko su niski kapaciteti orijentacije koju pruža levo-desna ideološka šema, onda se može očekivati njena mala upotrebljivost. Kada su ti kapaciteti mali? Koji činioci omogućavaju veću orijentaciju, a koji zbunjuju? Nema sumnje da kapaciteti orijentacije zavise od kapaciteta (pre svega saznajnih) samih građana, ali i od društvene situacije koja se interpretira i čija se promena želi ili ne želi, kao i od političkih aktera koji posreduju između građana i ,istorije“ (tj. date društvene situacije).

${ }^{7}$ Erih Oppenhuis kaže da je najizrazitija povezanost levo-desne dimenzije sa partijskim preferencijama utvrđena u Danskoj, Francuskoj, Nemačkoj i Grčkoj, gde ova ideološka dimenzija objašnjava iznad 30\% varijanse, dok je u ostalim zemljama oko $20 \%$, a u Irskoj i Severnoj Irskoj to je „prilično niže“ (1995: 126). - O. Knutsen (1995: 471) navodi da se korelacija između indeksa levo-desnog materijalizma i partijskog izbora u Francuskoj, Holandiji, Danskoj i Grčkoj, kreće između 0,45 i 0,47, dok u Irskoj svega 0,09. 
(4) Kapaciteti građana za upotrebu levo-desne ideološke šeme. Za prihvatanje ideološke LD šeme potreban je određen nivo političke pismenosti, kao i određen nivo zainteresovanosti za politiku (u pitanju je, dakle, politička kompetentnost).

(5) Priroda sadržaja koji se ideološki interpretiraju kroz levo-desnu šemu. Srbija je u ovim godinama izlazila iz jednog političkog sistema koji se smatrao (i smatra?) levim, istovremeno ulazeći u kapitalizam koji se smatrao (i smatra?) desnim. Intenzitet, širina i dubina tranzicionih mena, kao i dužina tranzicije i njen ne uvek jasan i pravolinijski pravac, sigurno predstavljaju činioce koji otežavaju ideološku LD interpretaciju svega toga, pa time i ideološko samorazumevanje građana.

(6) Stabilnost, doslednost i transparentnost ideološkog samoizjašnjenja i ideološke prirode osnovnih političkih aktera, političkih partija i političkih lidera, pre svih. Izrazitija stabilnost, veća doslednost, izraženija transparentnost političkih stranaka i lidera povećava upotrebu levo-desne ideološke šeme, dok obratni trendovi smanjuju upotrebu. U okviru ove tačke treba pomenuti empirijski proverljivu razliku u obimu upotrebe levo-desne ideološke šeme, zavisno od toga da li su u postkomunističkim zemljama bivše komunističke partije zadržale svoju ideologiju, što je bilo ređe, ili su se transformisale u socijaldemokratske partije, što je bio češći slučaj (opet sa Srbijom kao izuzetkom). Dok je, na primer, u 1991. godini prema nalazima istraživanja koje je obavio IRI (International Republican Institute) bilo $79 \%$ onih koji su se samosvrstali u ideološki LD kontinuum, dotle je godinu dana kasnije u Srbiji takvih građana bilo gotovo dvostruko manje $-43 \%$.

(7) I na kraju, upotrebna vrednost levo-desne šeme zavisi od praktične uverljivosti koncepta, od njegove „efikasnosti“. Ne može se ustvrditi da urušavanje socijalizma nije narušilo proporciju ne/prihvatanja levo-desne ideološke dimenzije. Kao što je teško poreći nalaz po kojem nestajanje „socijalne države“ nije uticalo na pomenutu proporciju.

Ukupno uzev, gotovo na svih sedam tačaka ove klasifikacije Srbija ima negativan rezultat. I upravo tu vidimo glavne tačke objašnjenja relativno niske upotrebe levo-desne šeme u političkom samorazumevanju građana Srbije. Mada je ideološka autoidentifikacija dimenzija političke kompetentnosti, naši nalazi pre govore o veoma naglašenoj afektivnoj dimenziji te kompetentnosti nego o osrednje razvijenoj saznajnoj dimenziji. Naš ispitanik oseća da pripada kontinumu, ali on ne zna, on nije u stanju da iole ozbiljnije obrazloži to „pripadanje“.

\section{Prepoznavanje lokacije sopstvene stranke u ideološkom levo-desno}

\section{prostoru}

Na početku četvrtog kvartala ovog dvocenijskog drugog života Demokratske stranke, relativna većina pristalica stranke spremna je da je identifikuje kao stranku levice. Konkretno $36 \%$ pristalica DS vidi svoju stranku na levici, $28 \%$ u centru a $23 \%$ na desnici, dok $13 \%$ nije u stanju da je identifikuje (tabela 2). Ne može se reći da nije čudno da gotovo četvrtina pristalica DS vidi svoju stranku kao desnu! 
Tabela 2 - Stranačka samoidentifikacija i ideološka levo-desna autoidentifikacija (u \%)

\begin{tabular}{|l|r|r|r|r|r|}
\hline & \multicolumn{1}{|c|}{ Levica } & \multicolumn{1}{l|}{ Centar } & \multicolumn{1}{l|}{ Desnica } & Ne zna & Ukupno \\
\hline SPS & 64 & 6 & 8 & 22 & 100 \\
\hline DS & 36 & 28 & 23 & 13 & 100 \\
\hline SRS & 24 & 12 & 49 & 15 & 100 \\
\hline DSS & 19 & 26 & 37 & 18 & 100 \\
\hline Nema blisku stranku & 16 & 26 & 17 & 41 & 100 \\
\hline
\end{tabular}
$\mathrm{Ck}=0,42$

Od četiri relevantne stranke u 2006. godini u dve je dominirala levica, a u druge dve - desnica (tabela 2). Najviše levo opredeljenih bilo je u Socijalističkoj partiji, gotovo dve trećine (64\%) ili osam puta više nego onih koji se prepoznaju kao desničari (u centru je svega $6 \%$, dok petina ne zna da se prepozna u ideološkom spektru). Među radikalima je svaki četvrti bio, po sopstvenoj oceni, levo orijentisan (!), a svaki drugi desno orijentisan (12\% je u centru, a $15 \%$ se ne prepoznaje u levo-desnoj šemi). U Demokratskoj stranci Srbije petinu su činili oni koji sebe prepoznaju kao levičare, gotovo dve petine sebe vidi na desnici, a u centru je svaki četvrti. Ovi nalazi otvaraju nekoliko važnih pitanja. Kakav je i koliko je to nivo političke kompetentnosti stranačkih pristalica kada među pristalicama četiri najvažnije stranke nalazimo $13-22 \%$ onih koji nisu u stanju da se orijentišu u jednoj gotovo dihotomnoj ideološkoj podeli na levo i desno? Potom, kako to da se gotovo svaki četvrti pristalica DS smatra desničarom? Kako to da gotovo svaki četvrti pristalica SRS sebe smatra levičarom? Da li su isti levičari u SPS-u i levičari u DS-u i levičari među radikalima i, na primer, oni koji su se našli u LDP? Isto pitanje važi i za ispitanike koji sebe smatraju desničarima! Da li su isti ili različiti levičari odnosno desničari - ili su, možda, stranke iste, odnosno različite?

Gotovo osam desetina levičara $(78 \%)$ pristaje uz partije koje smatra levim, 6\% uz partiju koju smatra desnom, 6\% uz partiju centra, a $10 \%$ ne zna da locira „svoju partiju“. Blizu devet desetina (87\%) od ukupnog broja desničara pristaje uz partiju koju smatra desnom, 5\% uz partiju koju smatra levom, $6 \%$ uz partiju centra, dok $2 \%$ ne zna gde da locira svoju stranku.

Kako građani različitih ideoloških orijentacija vide „levi karakter“ Demokratske stranke? Da li je uopšte vide kao levicu, ako je pak vide da li u njoj, možda, prepoznaju novu modernu levicu, ili možda tek levu frazeologiju?

Tabela 3 - Mnjenje o DS kao partiji levice i ideološka LD samoidentifikacija (u \%)

\begin{tabular}{|l|r|r|r|r|r|}
\hline & \multicolumn{1}{l|}{ Levica } & \multicolumn{1}{l|}{ Centar } & \multicolumn{1}{l|}{ Desnica } & Ne zna & \multicolumn{1}{l|}{ Prosek } \\
\hline DS jeste levica & 7 & 1 & 3 & 1 & 3 \\
\hline DS jeste levica, nova, moderna & 24 & 14 & 8 & 5 & 12 \\
\hline DS je lažna levica & 13 & 12 & 16 & 7 & 12 \\
\hline DS nije levica & 29 & 27 & 35 & 15 & 26 \\
\hline Danas se ne zna gde je ko & 27 & 46 & 38 & 72 & 47 \\
\hline Ukupno & 100 & 100 & 100 & 100 & 100 \\
\hline
\end{tabular}

$\mathrm{Ck}=0,36$ 
Nepuna trećina od ukupnog broja ispitanika koji sebe vide kao levičare (31\%) smatra da je DS na levici, dok to negira dve petine levičara (42\%); četvrtina pak $(27 \%)$ ne zna ili ne prihvata ideološku deobu na levicu i desnicu. Gotovo polovina centrista je zbunjena (,danas se ne zna gde je ko“) ili ne zna da se snađe u ovoj šemi, $15 \%$ vidi DS na levici, a to mišljenje negira dve petine (39\%). Desničari najčešće ne vide DS na levici (51\%) naspram $11 \%$ onih koji DS vide kao levu stranku, dok 38\% kaže da ne zna ili ne priznaje ovaj tip podela.

\section{Ideološki imidž Demokratske stranke}

Kako građani vide političke stranke? Šta vide i šta nalaze u njihovom programskom i ideološkom bagažu? Da bismo došli do odgovora na ovo pitanje trebalo je izabrati stranke i indikatore ideoloških orijentacija. Najlakše je bilo izabrati stranke. Od četiri stranke na čiju smo relevantnost računali $u$ istraživanju iz 2006. godine, izabrali smo tri između kojih smo očekivali da će se u percepciji građana javiti najveća razlika: Demokratska stranka, na jednoj strani, a Socijalistička partija Srbije i Srpska radikalna stranka na drugoj strani. Mnogo veći problem je bio vezan za određivanje i izbor indikatora globalnih ideoloških orijentacija, a shodno našem projektu reč je o ideološkoj šemi levodesno.

Najviše dvoumljenja bilo je u opredeljivanju između uslovno rečeno modela „Programskih prioriteta“ (Klingemann i drugi, 1994), relativno standardnog ispitivanja vrednosti i vrednosnih orijentacija (van Deth and Scarbrough, eds., 1995) i Manifesto-Based Measures of Ideology sa 26 kategorija koje pokazuju inklinaciju ka levim ili ka desnim tendencijama (Kim and Fording, 1998; Budge and Bara, 2001; Budge et al, 2001; Mc Lean, 2004). Svi ovi pristupi (kao i većina u ovom domenu) zahtevali su znatan prethodni rad za šta ovom prilikom nije bilo vremena, pa smo se odlučili za relativno arbitraran pristup. ${ }^{8}$ Tako smo testirali 14 vrednosti, odnosno 7 parova vrednosti (šema 1). U istraživanju smo od ispitanika tražili da od tih 14 vrednosti izabere po 5, po njegovom mišljenju karakterističnih za Demokratsku stranku, Socijalističku partiju Srbije i Srpsku radikalnu stranku.

${ }^{8}$ Jedan takav, reklo bi se pojednostavljen pristup daje Hejvud (2004: 471). Za njega su ideološke i vrednosne odredbe levice: sloboda, jednakost, bratstvo, prava, napredak, reforma, internacionalizam; a desnice: autoritet, hijerarhija, poredak, obaveze, tradicija, reakcija, nacionalizam. Zanimljivi su, u ovom kontekstu, nalazi Ivana Šibera iz 1986. godine kada je od ispitanika tražio da navedu sadržaje koje oni sami vezuju za pojam levice, odnosno za pojam desnice. Dobijeni odgovori svedoče o tadašnjem razumevanju LD šeme, a ne o današnjem, o stanju u Hrvatskoj, a ne o stanju u Srbiji. Upravo te naznačene (moguće) razlike upućuju na eventualno nisku mogućnost uopštavanja rezultata dobijenih nedorečenom upotrebom skale sa nedefinisanim pojmovima. Autor je u pomenutom istraživanju dobio da ispitanici uz odrednicu „levo“ vezuju: progres, socijalizam, ateizam, pozitivno, jednakost, samoupravljanje, poštenje; a uz odrednicu „desno“: konzervativizam, kapitalizam, religioznost, negativno, nejednako, standard, produktivnost (Šiber, 1991: 118). 
Šema 1 - Indikatori globalnih ideoloških orijentacija: levica vs. desnica

\begin{tabular}{|l|c|l|}
\hline Levica (socijaldemokratija) & vs. & Desnica (konzervativizam, neoliberalizam) \\
\hline modernost & $v s$. & tradicionalizam \\
\hline jednakost startnih pozicija & $v s$. & svako brine o sebi \\
\hline socijalna pravda & $v s$. & pravda je ono što kaže tržiste \\
\hline poštovanje svake ličnosti & $v s$. & poštovanje starijih \\
\hline kosmopolitizam & $v s$. & nacionalizam \\
\hline principijelnost & $v s$. & dogmatičnost \\
\hline nereligioznost & $v s$. & religioznost \\
\hline
\end{tabular}

Dobili smo rezultate koji su prilično kontradiktorni. Demokratsku stranku građani prvenstveno vide kao modernu, levu i socijaldemokratsku, ali istovremeno i kao neoliberalnu partiju (!!!). Oni je percipiraju preko suprotnosti modernost vs. tradicionalizam i preko dva para ajtema koji problematizuju suštinske elemente socijaldemokratske vs. neoliberalne ideologije. U jednom slučaju reč je o suprotstavljanju socijaldemokratskog zalaganja za jednakost startnih pozicija neoliberalnom načelu po kojem svako brine o sebi, a u drugom slučaju reč je o suprotstavljanju socijalne i tržišne pravde. Birači, dakle, vide Demokratsku stranku kao modernu stranku koja se zalaže za egoistično neoliberalno načelo po kojem svako brine o sebi i za „tržišnu“ a ne za socijalnu pravdu!

Tabela 4 - Ideološki imidž Demokratske stranke

\begin{tabular}{|c|c|c|}
\hline Vrednosni parovi & Procenat & Indeks levo $v s$. desno $(\operatorname{desno}=\mathbf{1 , 0})$ \\
\hline Modernost & 41 & 5,6 \\
\hline Tradicionalizam & 7 & 1,0 \\
\hline Jednakost startnih pozicija & 17 & 0,7 \\
\hline Svako brine o sebi & 25 & 1,0 \\
\hline Socijalna pravda & 15 & 0,7 \\
\hline Pravda je ono što kaže tržište & 24 & 1,0 \\
\hline Poštovanje svake ličnosti & 26 & 2,7 \\
\hline Poštovanje starijih & 10 & 1,0 \\
\hline Kosmopolitizam & 25 & 6,7 \\
\hline Nacionalizam & 4 & 1,0 \\
\hline Principijelnost & 16 & 1,5 \\
\hline Dogmatičnost & 11 & 1,0 \\
\hline Nereligioznost & 12 & 2,0 \\
\hline Religioznost & 6 & 1,0 \\
\hline Ukupno - levo & 64 & 1,8 \\
\hline Ukupno - desno & 36 & $\mathbf{1 , 0}$ \\
\hline
\end{tabular}


Gledajući širi spisak vrednosti, možemo reći da birači prvenstveno vide DS kao modernu stranku (41\%), stranku koja se zalaže za poštovanje svake ličnosti (26\%), stranku koja je drži do kosmpolitizma (25\%) i kao stranku koja se zalaže za tržišnu pravdu (24\%). Najređe su kao obeležja imidža DS navođeni: nacionalizam (4\%), religioznost (6\%) i tradicionalizam (7\%). Dve najveće ideološke suprotnosti koje obeležavaju imidž Demokratske stranke jesu kosmopolitizam vs. nacionalizam (proporcija 6,7 prema 1) i modernost $v s$. tradicionalizam (5,6 prema 1).

O ideološkom imidžu Demokratske stranke izjasnilo se tri petine biračkog tela (2\% manje nego za SRS). Uz dosta uopštavanja može se tvrditi da se Demokratska stranka percipira kao stranka moderne levice uz naglašen neoliberalan pristup u sferi ekonomije. U klasičnoj literaturi se ova vrsta dvojnosti smatra neodrživim protivrečjem, dok se u modernim pristupima pokazuje izvesno razumevanje za naznačenu kontrarnost. Dok su na drugoj strani ovakve kolizije ili „kolizije“ u političkoj praksi (na primer, zastupnika „trećeg puta“, „,novog centra" i dr.) sve češće!

Socijalističku partiju Srbije građani vide kao nereligioznu (23\%), dogmatsku (22\%), egoističnu (21\% - „svako brine o sebi“), nacionalističku (21\%), stranku kojoj je stalo do socijalne pravde (19\%), tradicionalističku (18\%) $i$ stranku koja se zalaže za poštovanje starijih (17\%). SPS se percipira preko jedne suprotnosti koja indicira relaciju socijaldemokratija / neoliberalizam - jednakost startnih pozicija vs. egoizma (,svako brine o sebi“), a potom preko jedne suprotnosti koja faktički iskazuje dominantnost starijih pristalica ove stranke - poštovanje svake ličnosti $v s$. poštovanja starijih. Tu je još principijelnost $v s$. dogmatičnosti, socijalna $v s$. tržišne pravde i ne/religoznost $v s$. religioznosti koja je istovremeno vrednosni par u kojem je do izražaja došla najveća razlika - 6,3 prema 1 .

O ideološkom imidžu Srpske radikalne stranke izjasnilo se 57\% biračkog tela. Iako je taj imidž dominantno imidž jedne desne, konzervativne stranke - treba istaći izvesno dvojenje, koje može ali i ne mora da bude protivrečno u glavama naših ljudi. Naime, $44 \%$ od ukupnog biračkog tela vidi Radikalnu stranku kao nacionalističku stranku (nekim to smeta, a nekima ne), a istovremeno tu je i 16\% onih koji SRS vide kao stranku koja se zalaže za ostvarivanje socijalne pravde.

Tabela 5 - Ideološki imidž DS, SPS i SRS

\begin{tabular}{|l|r|r|r|}
\hline Vrednosni parovi & $\begin{array}{l}\text { Demokratska } \\
\text { stranka }\end{array}$ & $\begin{array}{l}\text { Socijalistička } \\
\text { partija Srbije }\end{array}$ & $\begin{array}{l}\text { Srpska radikal- } \\
\text { na stranka }\end{array}$ \\
\hline Kosmopolitizam & 25 & 4 & 3 \\
\hline Nacionalizam & 4 & 21 & 44 \\
\hline Modernost & 41 & 4 & 5 \\
\hline Tradicionalizam & 7 & 18 & 31 \\
\hline Nereligioznost & 12 & 23 & 5 \\
\hline Religioznost & 6 & 4 & 25 \\
\hline Socijalna pravda & 15 & 19 & 16 \\
\hline
\end{tabular}




\begin{tabular}{|l|r|r|r|}
\hline $\begin{array}{l}\text { Pravda je ono što kaže trži- } \\
\text { šte }\end{array}$ & 24 & 8 & 9 \\
\hline Poštovanje svake ličnosti & 26 & 14 & 13 \\
\hline Poštovanje starijih & 10 & 17 & 12 \\
\hline Jednakost startnih pozicija & 17 & 11 & 10 \\
\hline Svako brine o sebi & 25 & 21 & 14 \\
\hline Principijelnost & 16 & 7 & 16 \\
\hline Dogmatičnost & 11 & 22 & 21 \\
\hline Ukupno - levo & $\mathbf{6 4}$ & $\mathbf{4 3}$ & $\mathbf{3 1}$ \\
\hline Ukupno - desno & $\mathbf{3 6}$ & $\mathbf{5 7}$ & $\mathbf{6 9}$ \\
\hline
\end{tabular}

Dva najčešća vizira kroz koja su gledani ideološki bagaži političkih stranaka bili su vrednosni par kosmopolitizam $v s$. nacionalizam i modernost $v s$. tradicionalizam (tabela 5). Preko prvog vrednosnog para SPS je gledao svaki četvrti punoletan građanin Srbije, Demokratsku stranku negde između svakog trećeg i svakog četvrtog, a SRS gotovo svaki drugi. Preko drugog vrednosnog para (modernost / tradicionalizam) DS je gledao gotovo svaki drugi građanin, SRS svaki treći, a SPS - svaki četvrti.

Istovremeno, u ovim vrednosnim parovima dolazilo je do najveće razlike u percepcije ove tri političke stranke. Tako se u slučaju nacionalizma javila razlika između DS (4\%) i SRS (44\%) od čak jedanaest puta, odnosno građani su nacionalizam 11 puta češće pripisivali radikalima nego demokratama (socijalisti su negde u sredini, ali nešto bliži radikalima $-21 \%$ prema $44 \%$ ).

Slično je i sa modernošću. Građani su deset puta češće modernost vezivali za Demokratsku stranku nego za radikale, a osam puta češće za demokrate nego za socijaliste. U ovom slučaju na jednoj strani, na strani modernosti je Demokratska stranka, a na drugoj, odnosno na strani tradicionalizma su SPS i SRS.

S druge strane, najmanje su navođeni vrednosni parovi (istovremeno tu su i najmanje razlike između stranaka): principijelnost vs. dogmatičnost, jednakost startnih pozicije vs. ,svako brine o sebi“ i poštovanje svake ličnosti vs. poštovanja starijih. Dogmatičnost je, na primer, dva puta ređe navođena u slučaju DS nego u slučajevima SPS i SRS. Načelo da se svako brine za sebe građani gotovo dva puta češće pripisuju Demokratskoj stranci (25\%) nego radikalima (14\%). Socijalisti (21\%) su bliži demokratama nego radikalima. Treba pomenuti i vrednosni par poštovanje svake ličnosti vs. poštovanje starijih gde je Demokratskoj stranci dva puta češće pripisivano poštovanje svake ličnosti nego radikalima i socijalistima. 


\section{Zaključak: Društveni stavovi - zbrka u glavi ili zbrka u stvarnosti}

Za zaključak prvo smatram relevantnim viđenje Demokratske stranke od punoletnih građana Srbije (tabela 6). Samo $15 \%$ građana DS prepoznaje kao stranku levice prema istraživanju iz 2006. godine; $12 \%$ je vidi kao lažnu levicu, dok $26 \%$ smatra da ona nije stranka levice (svi ostali, gotovo polovina građana, nije u stanju da se izjasni). U tumačenju ovih nalaza treba imati na umu da ideološka šema levo-desno ipak funkcioniše u našem razumevanju politike i da većina građana funkcionalno upotrebljava ove pojmove.

Tabela 6 - Mnjenje o DS kao partiji levice i ideološka LD samoidentifikacija (u \%)

\begin{tabular}{|l|r|r|r|r|r|}
\hline & \multicolumn{1}{|l|}{ Levica } & \multicolumn{1}{l|}{ Centar } & \multicolumn{1}{l|}{ Desnica } & Ne zna & \multicolumn{1}{l|}{ Prosek } \\
\hline DS jeste levica & 31 & 15 & 11 & 6 & 15 \\
\hline DS je lažna levica & 13 & 12 & 16 & 7 & 12 \\
\hline DS nije levica & 29 & 27 & 35 & 15 & 26 \\
\hline Danas se ne zna gde je ko & 27 & 46 & 38 & 72 & 47 \\
\hline Ukupno & 100 & 100 & 100 & 100 & 100 \\
\hline
\end{tabular}

$\mathrm{Ck}=0,36$

Doduše, u istraživanju nismo mogli da pokažemo zasnovanost levodesnog ideološkog opredeljenja na nizu stavova koji su indikovali to opredeljenje. Po svemu sudeći, levo-desno opredeljenje je zasnovano na površnim, nejasnim i neodređenim impresijama, koje su ipak (što je gotovo neverovatno) stalnog karaktera. Istovremeno prihvatanje oprečnih ideoloških stavova dovodi u pitanje logiku ove podele, dok relativno konsekventna upotreba tih pojmova u političkoj praksi opravdava funkcionalnu pragmatičnost date ideološke podele! Sve u svemu, Demokratskoj stranci treba još mnogo toga da bi je javnost percipirala kao stranku levice.

Druga serija podataka relevantna za zaključak o karakteru Demokratske stranke, odnosno njenih pristalica, jeste odnos simpatizera DS prema nacionalizmu, komparativno sa pristalicama drugih relevantnih stranaka (tabela 7).

Tabela 7 - Odnos prema naciji - 1990, 1993, 2004, 2007. i 2010. godine (u \%)

\begin{tabular}{|l|c|r|r|r|r|r|}
\hline Indicije nacionalizma & Godina istraživanja & DS & \multicolumn{1}{|c|}{ DSS } & SPO & \multicolumn{1}{c|}{ SPS } & SRS \\
\hline Tvrda nacionalna orijentacija & 1990. & 70 & $*$ & 90 & 66 & $*$ \\
\hline Tvrda nacionalna orijentacija & 1993. & 79 & 80 & 69 & 92 & 97 \\
\hline $\begin{array}{l}\text { „Glasam za stranke koje doprinose } \\
\text { nacionalnom interesu, makar živeli } \\
\text { i lošije“ }\end{array}$ & 2004. & 20 & 33 & 36 & 58 & 53 \\
\hline Velika etnička distanca & 2006. & 32 & 34 & $*$ & & 59 \\
\hline Nacionalistička orijentacija & 2007. & 20 & 38 & $*$ & 75 & 77 \\
\hline $\begin{array}{l}\text { Etnička distancu prema Hrvatima } \\
\text { barem po jednom od 4 kriterijuma }\end{array}$ & 2010 & 55 & 74 & $*$ & 64 & 77 \\
\hline
\end{tabular}


Izvori: Za 1990. i 1993. godinu - istraživanja Centra za politikološka istraživanja i javno mnjenje IDN, za 2004, 2007. i 2010. godinu - istraživanje CeSID-a.

Napomene: Ispitivanje nacionalizma 1990. i 1992. obavljeno je na isti način dok je 2007. rađeno drukčije - tu razliku smo nastojali da istaknemo razlikom u nazivu kategorija: jednom je to „tvrda nacionalna orijentacija“, a drugi put „nacionalistička orijentacija“. U tabeli u redu za 1990. godinu zvezdicama je označeno nepostojanje datih stranaka, a u redu za 2007. godinu - nedovoljan broj pristalica date stranke u istraživačkom uzorku (stoga nije bilo korektno dati podatke za ovu stranku).

Reč je o nacionalizmu upravo zbog onoga što smo rekli na početku članka: zato što je on crna rupa socijalnog kapitala u Srbiji i što bez pacifikacije ovog pitanja Srbija ne može računati na boljitak. Podaci kojima raspolažemo, iako mere nacionalizam različitim metrima (zbog toga podatke treba uzimati sa velikom rezervom ${ }^{9}$ ), govore o „krivudavoj“ linija opadanja i rasta nacionalizma. Nesumnjiva linija opadanja počev od sredine 1990-ih nije išla jednolinijski. S druge strane, pristalice Demokratske stranke su u gotovo svim posmatranim godinama imale pozitivniji odnos prema „drugima“ od pristalica ostalih stranaka; razlika nije uvek bila izrazita ali je postojala i u poslednjem petogodištu postala je prilično velika.

\section{Literatura}

Beyme, Klaus von. 2002. Transformacija političkih stranaka. Zagreb: Fakultet političkih znanosti Sveučilišta u Zagrebu.

Kitschelt, Herbert et al. 1999. Post-Communist Party Systems: Competition, Representation, and Inter-Party Cooperation. Cambridge University Press.

Mair, Peter. 1998. Party System change. Approaches and Interpretations. Clarendon Press - Oxford.

Mihailović, Srećko. 1994. „Ideološki profil stranačkih pristaša“. Sociološki pregled. Vol. XXVIII. No 1.

Mihailović, Srećko. 2006. „Dugo putovanje u kapitalizam“. U: Mihailović, S. (ur.). Pet godina tranzicije u Srbiji II. Beograd: Socijaldemokratski klub i Fridrih Ebert fondacija. Mihailović, Srećko, Zoran Stojiljković, Đorđe Vuković, Zlatko Šram i Miloš Mojsilović. 2005. Političke podele i vrednosne orijentacije građana Srbije. Beograd: CeSID (umnoženo).

Pantić, Dragan. 2002. „Vrednosti birača pre i posle demokratskog preokreta 2000. godine“. U: Goati, V. (ur.). Partijska scena Srbije posle 5. oktobra 2000. Beograd: FES i IDN.

Pantić, Dragan. 2003. „Kulturno-vrednosni rascepi kao determinante partijskog pregrupisavanja u Srbiji“. U: Komšić, Pantić, Slavujević. Osnovne linije partijskih podela. Beograd: Institut društvenih nauka.

Šram, Zlatko. „Socijalni stavovi i osobine ličnosti kao komponente političke kulture“. U: Vukomanović, Dijana. 2007. „Ideološke matrice političkih partija u Srbiji (1990-2007)“, U: Lutovac, Z. (ur.) Ideologija i političke stranke u Srbiji. Beograd: FES i drugi.

${ }^{9}$ Između ostalog, u tabeli 7 podatke ne treba čitati po kolonama već po redovima, jer se komparacije mogu vršiti samo između pristalica različitih stranaka, ali ne i unutar pristalica jedne stranke u različitim godinama. Upravo zbog različitih načina merenja odnosa prema nacionalizmu). 